\title{
Commentary on How common is sleep-disordered breathing in patients with idiopathic pulmonary fibrosis? Mermigkis C. et al.
}

\author{
Karl-Heinz Ruhle
}

Received: 9 February 2010 /Revised: 9 February 2010/Accepted: 10 February 2010/Published online: 16 March 2010

(C) Springer-Verlag 2010

There are few recent studies on the issue of quality of sleep in interstitial lung disease [idiopathic pulmonary fibrosis (IPF)]. Early studies [1,2] showed that the patients developed significant desaturation during sleep, especially during REM sleep. In a comparative study with a healthy control group using PSG monitoring, $\mathrm{SaO} 2$ was reduced below 90\% during $30 \%$ of sleep time. Furthermore, increased arousal, decreased sleep efficiency, and reduced Delta-sleep was found. These sleep disturbances had an effect on the subjective state/functionality, as measured by FOSQ and Pittsburgh (PSQI) [3]. Only recently, polysomnographic studies on the incidence of obstructive sleep apnea (OSA) in pulmonary fibrosis have been published $[4,5]$.

Data by Lancaster et al. [5] show an increased incidence of OSA in IPF patients. Forty-four of 50 subjects (88\%) had OSA as defined by an AHI of $>5$ events per hour. Twenty percent of subjects had mild OSA (AHI, five to 15 events per hour), and $68 \%$ had moderate-to-severe OSA (AHI $>15$ events per hour). The mean BMI of the whole group with OSA was 33. OSA was noted only in a small percentage of $11 \%$ of patients with normal BMI.

In this issue of SLBR, Mermigkis et al. [6] analyzed the frequency of OSA in 34 IPF patients. In a prospective study, they investigated Sleep Disordered Breathing isorders (SRBD) in a newly diagnosed IPF population group before the start of any treatment and tried to identify correlations with pulmonary function testing parameters. They found a high prevalence of SDB and a statistically significant correlation of REM AHI with TLC. The BMI was only moderately increased and at least in mild to moderate OSA

\section{K.-H. Ruhle $(\bowtie)$}

Department of Pneumology, HELIOS-Clinic Ambrock,

Ambrockerweg 60,

58091 Hagen, Germany

e-mail: Klinik-Ambrock.Pneumo@t-online.de
(AHI 5-15) not different from the BMI of the IPF patients without OSA $(\mathrm{AHI}<5)$. Thus, other additional factors should be responsible for the higher incidence of SRBD in IPF. Studies suggest that the mechanism underlying this association is probably a decrease in upper airway stiffness with lower lung volume caused by reduced caudal traction from the trachea.

The results demonstrate that sleep-disordered breathing in IPF is more frequent than previously suspected .These patients currently have very limited therapeutic options concerning the fibrosing alveolitis. We need to turn greater attention to the association between IPF and OSAS because applying CPAP sleep and quality of life can eventually be ameliorated. We should not defer sleep testing.

\section{References}

1. Bye PT, Issa F, Berthon-Jones M, Sullivan CE (1984) Studies of oxygenation during sleep in patients with interstitial lung disease. Am Rev Respir Dis 129:27-32

2. Perez-Padilla R, West P, Lertzman M, Kryger MH (1985) Breathing during sleep in patients with interstitial lung disease. Am Rev Respir Dis 132:224-229

3. Krishnan V, McCormack MC, Mathai SC, Agarwal S, Richardson B, Horton MR, Polito AJ, Collop NA, Danoff SK (2008) Sleep quality and health-related quality of life in idiopathic pulmonary fibrosis. Chest 134(4):693-698

4. Lancaster LH, Mason WR, Parnell JA, Rice TW, Loyd JE, Milstone AP, Collard HR, Malow BA (2009) Obstructive sleep apnea is common in idiopathic pulmonary fibrosis. Chest 136(3):772-778

5. Mermigkis C, Chapman J, Golish J, Mermigkis D, Budur K, Kopanakis A, Polychronopoulos V, Burgess R, Foldvary-Schaefer N (2007) Sleep-related breathing disorders in patients with idiopathic pulmonary fibrosis. Lung 185:173-178

6. Mermigkis C, Stagaki E, Tryfon S, Schiza S, Amfilochiou A, Polychronopoulos V, Panagou P, Galanis N, Kallianos A, Mermigkis D, Kopanakis A, Varouchakis G, Kapsimalis F, Bouros D. How common is sleep disordered breathing in patients with idiopathic pulmonary fibrosis? Sleep Breath. doi:10.1007/s11325-010-0336-5 